\title{
"Coisa de menina" e "coisa de menino"? Uma leitura do preconceito de gênero pela perspectiva dos praticantes de balé clássico masculino e futebol feminino
}

\author{
Tainá Nunes ${ }^{1}$ \\ Clara Schlichta ${ }^{2}$ \\ Luara Franco Valente dos Santos ${ }^{3}$ \\ Milena Camilla Pereira Maia ${ }^{4}$ \\ Pauline Vitória de Souza Ferreira ${ }^{5}$ \\ Vinícius Teixeira de Melo ${ }^{6}$ \\ Recebido em março de 2021 \\ Aceito em junho de 2021
}

\section{RESUMO}

Um reflexo do machismo estrutural na sociedade é a criação de estereótipos de gênero, que determinam o que é aceitável para homens ou mulheres, estigmatizando certas práticas corporais. Este artigo buscou evidenciar os preconceitos sofridos por dois grupos - mulheres no futebol e homens no balé clássico - a partir de suas próprias percepções, através de um questionário com perguntas abertas e fechadas. A análise dos dados fez uso das categorias sociológicas apresentadas por Marchi Júnior, Almeida e Souza (2019), para explicar os fenômenos sociais e qualificar uma leitura preliminar do tema.

Palavras-chave: Balé; Futebol; Gênero; Preconceito; Machismo.

"Girl activity" and "boy activity"? A reading of gender prejudice from the perspective of male classical ballet and female soccer practitioners

\begin{abstract}
One manifestation of the society's structural sexism is the creation of gender stereotypes, which determine what is acceptable for men or women, stigmatizing certain physical practices. This article sought to evidence the prejudices suffered by two groups - women in soccer and men in classical ballet - from their

${ }^{1}$ Cursando bacharelado em Educação Física na Universidade Federal do Paraná (UFPR). Participante do Centro de Pesquisa em Esporte, Lazer e Sociedade (CEPELS). E-mail: taina.nunes8@gmail.com.

${ }^{2}$ Bacharel em Educação Física pela Universidade Federal do Paraná. E-mail: clara.sch@hotmail.com.

3 Bacharel em Educação Física pela Universidade Federal do Paraná. E-mail: luara.franco@hotmail.com.

4 Bacharel em Educação Física pela Universidade Federal do Paraná. E-mail: milenacamilla.1o@hotmail.com.

5 Cursando bacharelado em Educação Física na Universidade Federal do Paraná. E-mail: paulinevitoria_sf@hotmail.com.

${ }_{6}$ Cursando bacharelado em Educação Física na Universidade Federal do Paraná. E-mail: vymelo8@gmail.com.
\end{abstract}


own perceptions, through a questionnaire with open and closed questions. The data analysis used the sociological categories presented by Marchi Júnior, Almeida e Souza (2019), to explain the social phenomena and qualify a preliminary reading of the theme.

Key-words: Ballet; Soccer; Gender; Prejudice; Sexism.

Existe um entendimento, socialmente motivado, de que através das normas, símbolos e atitudes dos seres humanos se promove aquilo que é feminino ou masculino em cada cultura. Nesse modelo de pensamento, objetos e atividades são impostos para o sexo designado fêmea/macho ao nascer, apenas levando em consideração o fator biológico. No entanto, em contraposição à biologização sugerida pelos atributos do sexo, o conceito de gênero surge-nos aqui como uma categoria, pois leva em conta fatores sociais, históricos e culturais do sujeito, ou seja, não há conceitos pré-existentes, uma vez que as identidades de gênero são mutantes e mutáveis (BERGER, LUCKMANN, 1978). Assim, o estereótipo para cada gênero, ou seja, o que é considerado um padrão de feminilidade ou masculinidade, não consiste em uma determinação biológica, e sim em uma construção social, podendo, portanto, variar não só entre diferentes sociedades, mas também dentro de uma mesma sociedade, com o decorrer do tempo (KIMMEL, 1998).

No sentido de restringir alguma prática a apenas um sexo, a sociedade tem um olhar característico de que a dança é de um universo predominantemente feminino, o que é ainda mais acentuado no balé clássico (SOUZA, 2007). Entretanto, esse nem sempre foi o cenário, pois, desde o seu surgimento, no Renascimento europeu, o balé clássico se manteve por muito tempo como uma pedagogia eficiente de masculinidade, um modo de se movimentar da nobreza. Do século XV até o século XVIII, a dança figurava, junto a esportes como esgrima e equitação, no rol de atividades físicas vistas pela sociedade como eficientes para a formação dos homens da elite, em uma sociedade de corte cada vez mais preocupada com a etiqueta e a imagem (BOURCIER, 2001). Essas práticas eram associadas a um modelo masculino da época, chamado por Kimmel (1998, p. 109) de "patriarca gentil" que era o perfil de um nobre europeu, aristocrático, refinado e elegante, de quem eram esperadas movimentações suaves e delicadas, com certa sensualidade. 
Entre a metade do século XVIII e o início do XIX, a Revolução Industrial promove o surgimento de um novo modelo de masculinidade, associado com a eficiência, racionalidade e produtividade. Kimmel (1998, p. 111) relata que este ideal surge tanto nos Estados Unidos quanto na Europa, chamado de "self made man", que é descrito como um empresário urbano, devotado ao trabalho, viril e competitivo. Nesse modelo, o homem tem que reafirmar sua masculinidade constantemente, não só por atributos físicos, mas também através de suas conquistas materiais.

Para instalar essa nova ideia de masculinidade como hegemônica, foi necessário negar a anterior, de modo que o modelo do patriarca gentil passou a ser um símbolo do que a nova representação desprezava. Assim, o balé clássico, que em seus primórdios sequer podia ser praticado por mulheres, gradualmente passou a ser considerado uma prática adequada apenas para o gênero feminino. Com isso se construiu a ideia de que o homem que dança não é totalmente homem (ANDREOLI, 2010).

Andreoli (2010), ao entrevistar homens inseridos no contexto da dança, constatou alguns fenômenos que acabam se repetindo entre os entrevistados, em decorrência deste modelo de masculinidade que ecoa até os dias atuais. Um deles é um início mais tardio dos homens na dança se comparados com as mulheres, que muitas vezes são inseridas no balé pelos pais a partir dos três anos de idade. Para os meninos, criam-se barreiras que acabam dificultando uma identificação com essa prática corporal, já que não recebem o estímulo para a dança, e sim a inibição e muitas vezes proibição, visto que desde a infância, no convívio escolar, familiar e em outros ambientes, se aprende a fazer distinção de práticas e costumes que são indicados a mulheres ou aos homens.

Além da representação cultural da dança associada à feminilidade, outro obstáculo é a condição de "artista”, que de modo geral não é vista como um projeto de vida bem sucedido, pois tem a imagem de não proporcionar boa remuneração. Geralmente esses bailarinos, devido ao modelo de self made man, procuram de alguma maneira legitimar sua prática. Muitos deles o fazem adotando o objetivo de se profissionalizarem e serem muito bons, se destacando para serem devidamente aceitos. Nessa intenção de buscar validação em relação à masculinidade, ocorre também a adoção de um discurso ressaltando como o balé é similar a um esporte em relação às 
exigências físicas, mostrando que eles também possuem características consideradas masculinas, como a força (ANDREOLI, 2010).

A associação do homem que dança balé como afeminado e homossexual, além de errônea, carrega consigo uma série de preconceitos, julgamentos de valores e discriminação, já que estamos em uma sociedade machista e heteronormativa (LEITE, 2011). Andreoli (2010, p. 17), conceitua heteronormatividade como "a noção de que a nossa cultura institui que a identidade heterosexual é a única identidade sexual normal e que, para ela se constituir, precisa necessariamente negar todas as outras formas de sexualidade, consideradas 'anormais'”. Ele aponta que essa ideia dá origem à homofobia social, além de reforçar a visão binária e limitante de gêneros, atuando em conjunto com a ideia de um modelo de masculinidade único e hegemônico.

A dominância desta masculinidade única se dá pela negação e inferiorização do "outro", e Kimmel afirma que "as mulheres e os homens gays são os outros clássicos, o pano de fundo contra o qual os homens brancos heterossexuais projetam as suas ansiedades de gênero, e é sobre a emasculação destes que os self-made men constroem definições hegemônicas". Assim, são marginalizados não só os indivíduos de fato homossexuais, mas qualquer pessoa que escape do que é esperado para seu gênero, baseado nessa dicotomia construída definindo o que é feminino ou masculino.

Algo análogo ocorre com o futebol, que é comumente associado ao vigor e ao empenho físico masculinos (TEIXEIRA; CAMINHA, 2013). Entrelaçado a isso, a exigência de feminilidade, sensibilidade e beleza da mulher leva a alguns discursos privativos sobre a mulher praticante de futebol (GOELLNER, 2005). Kessler (2012) observa na mídia um dos reflexos dessa valorização da masculinidade no futebol: ainda há reportagens falando apenas da beleza de atletas mulheres, ao invés de sua habilidade no esporte, e quando uma jogadora de destaque na modalidade é elogiada de fato por quesitos técnicos e bons resultados, muitas vezes é através da associação com um homem, em expressões como "Pelé de saias".

Historicamente, as mulheres entraram neste universo tardiamente em comparação aos homens, com os primeiros registros de uma participação mais organizada no futebol a partir do ano de 1917, na Inglaterra. Elas estavam tendo uma vida ativa nas fábricas, uma vez que os homens estavam em combate na I Guerra Mundial. 
Isso deu às mulheres a oportunidade de se interessarem por práticas que antes não tinham acesso. Naquele ano, em uma fábrica de munição no norte da Inglaterra, por exemplo, algumas mulheres fundaram um time que, em 1920, foi protagonista do primeiro jogo internacional de futebol feminino, contra a França. Em 1921, o time inglês estava no seu auge, porém, com a volta dos homens da guerra, a Federação Inglesa de Futebol proibiu as mulheres de praticarem a modalidade, com a justificativa de que esta prática seria prejudicial para a saúde delas. Esta proibição não é observada apenas na Inglaterra: países como Alemanha e Brasil têm o mesmo fato contado em suas histórias (PISANI, 2014).

No Brasil, até a década de 40 a prática feminina estava distante de clubes ou grandes ligas. Entretanto, sabe-se que já aconteciam alguns jogos, como o ocorrido entre “senhoritas” de bairros de São Paulo, em 1921. Além das práticas mais elitizadas, o futebol se popularizou em espaços informais, como as praias (principalmente no Rio de Janeiro), periferias e até circos, neste caso já havendo forte estigmatização sobre os corpos femininos (MARTINS; SILVA; VASQUEZ, 2021). O futebol era visto como um esporte violento, que poderia prejudicar as mulheres, ferindo seus órgãos reprodutores (VIANA, 2008).

Em 1941, sob pedidos da parte mais conservadora da população, Getúlio Vargas instituiu um decreto (lei 3199, art. 54) no qual dizia, de forma geral, que as mulheres não deveriam praticar esportes que não fossem adequados à sua natureza. Deve-se ressaltar que houve focos de resistência e desobediência à proibição ao longo dos anos, mas o desenvolvimento da modalidade ficou quase estagnado neste período (GOELLNER, 2021). Diante de práticas ilegais da modalidade, em 1965 o governo militar tornou a legislação ainda mais rigorosa, havendo registros de mulheres que até foram presas (VIANA, 2008).

Em 1970, houve a criação da Federação Internacional de Futebol Feminino, que culminou no fim da proibição da modalidade na Inglaterra e na Alemanha. Contudo, o Brasil ainda vivia em um cenário que proibia as mulheres de praticar este esporte. Somente no final da década de 70 que a lei brasileira foi revogada, autorizando-as a jogarem. Porém, apenas em 1983 a modalidade foi regulamentada, permitindo competições e a utilização dos estádios. Naquele ano ocorreu em Porto Alegre o primeiro 
jogo organizado por uma federação. Incentivados pela regulamentação, foram surgindo novas competições e novos times, alguns que já jogavam clandestinamente (GOELLNER, 2021).

A primeira Copa do Mundo feminina aconteceu em 1991, na China. A Confederação Brasileira de Futebol (CBF) assumiu a seleção oficialmente, porém, de forma amadora. A equipe foi formada a partir de um time que se destacava no Rio de Janeiro, e as jogadoras não podiam sequer fazer o uso das estruturas da Granja Comary, centro de treinamento (CT) da seleção de futebol masculina. Em 1996, o futebol feminino estreou nos Jogos Olímpicos, que ocorreram em Atlanta, nos Estados Unidos. Apenas em 2004, na preparação para os Jogos Olímpicos na Grécia, que houve relatos da seleção feminina treinando no $\mathrm{CT}$, mas ainda com diversas dificuldades, não podendo utilizar toda a estrutura que o espaço oferecia. No ano de 2009, aconteceu a primeira Copa Libertadores da América feminina e só em 2013 o primeiro campeonato brasileiro.

Um avanço que deve ser mencionado é a obrigatoriedade dos times masculinos da série A terem uma equipe feminina a partir de 2019, decisão tomada em 2017 pela Confederação Sul-americana de Futebol (Conmebol). Aconteceu em 2019, na França, a mais recente Copa do Mundo de futebol feminino. Ficou evidente um cenário de maior visibilidade, pois os jogos da seleção brasileira foram transmitidos por mais de uma emissora de TV aberta, além de estádios lotados. Houve também uma maior valorização por parte da FIFA (Federação Internacional de Futebol), a qual aumentou significativamente o valor da premiação para as seleções participantes.

$\mathrm{Na}$ equipe que elaborou este artigo, há uma mulher praticante de futebol/futsal, que sentiu muito desse preconceito na sua vivência da modalidade. Outra integrante é praticante e professora de balé clássico e, apesar de pertencer ao gênero socialmente aceito para esta atividade, pôde observar a escassez de homens e meninos nesse meio, e as dificuldades sofridas pelos que querem se dedicar a essa arte. A partir destas experiências, definiu-se o objetivo do presente artigo: evidenciar o preconceito sofrido por homens no balé clássico e mulheres no futebol; duas práticas corporais muito distintas, mas com a semelhança de carregarem um forte estereótipo de gênero. 


\section{Metodologia}

Realizou-se uma pesquisa transversal do tipo descritiva, em que homens, do universo do balé clássico, e mulheres, do universo do futebol, responderam um questionário com questões abertas e fechadas. Esse tipo de pesquisa nos permite conhecer diretamente a realidade das pessoas, suas opiniões e atitudes, obtendo resultados tanto quantitativos quanto qualitativos (GIL, 2017).

Sob o viés do balé clássico, participaram desta pesquisa sete homens, três autodeclarados praticantes amadores de balé clássico e quatro autodeclarados profissionais dessa modalidade, atuantes na cidade de Curitiba/PR e com idade média de $27,8 \pm 4,8$ anos. Os primeiros entrevistados eram professores ou alunos da escola de dança frequentada por uma das autoras. Entretanto, devido à pequena quantidade de bailarinos, foi aceito que esses participantes indicassem conhecidos que também se enquadrassem no perfil desejado, mesmo sendo de outras escolas/companhias.

Sob o viés do futebol, participaram onze mulheres autodeclaradas não profissionais, atuantes na cidade de Curitiba/PR e com idade média de 21,4 $\pm 2,2$ anos. Todas eram atletas de um time universitário de futsal. Apesar do time não ser especificamente de futebol, consideramos válido para esta análise, já que são esportes similares, sofrendo dos mesmos estereótipos. Além disso, a maioria das entrevistadas tem alguma experiência em ambas as modalidades.

A coleta de dados foi realizada em ocasiões diferentes, antes ou após horários de aulas ou treino dos participantes. Os questionários foram respondidos de forma escrita e aplicados individualmente, em local confortável e sem interferências que pudessem prejudicar o andamento da coleta. Os pesquisadores não interferiram, mas estavam presentes para sanar quaisquer dúvidas em relação ao conteúdo do questionário. Em relação à parte quantitativa, os dados foram tratados por meio de estatística descritiva, utilizando o programa Microsoft Excel 2016 para obter a frequência das respostas. 


\section{Resultados e discussão}

Ao elaborar uma análise sociológica como esta, é necessária a atenção ao método científico, com embasamento em preceitos teórico-metodológicos que garantam uma boa leitura e análise do senso comum, e não apenas sua reprodução em um formato pseudo-acadêmico. Portanto, para qualificar a leitura dos fenômenos observados, lançamos mão das categorias sociológicas apresentadas por Marchi Júnior, Almeida e Souza (2019, p. 135), que, de acordo com os próprios autores, "são conceitos que geralmente se relacionam a uma teoria, mas que, sozinhos, também têm potencial para explicar fenômenos sociais complexos”.

Também utilizamos conceitos da Teoria Reflexiva dos Campos, elaborada por Pierre Bourdieu, pois ela ajuda a entender as disputas por poder e legitimidade, além de considerar a influência das construções sócio-históricas nas atitudes dos indivíduos. Um desses conceitos é o habitus, que foi resumido por Marchi Júnior, Almeida e Souza (2019, p. 128) como "as disposições que determinam as formas de se perceber, sentir, fazer, pensar e agir que levam o agente a determinadas condutas dentro do campo".

Em sua obra A Dominação Masculina, Bourdieu (2019) resgata a origem da dominação dos homens sobre as mulheres, que acabou culminando nos preconceitos impregnados na estrutura da sociedade atual, influenciando tanto o campo da dança quanto do esporte, e consequentemente o habitus dos agentes envolvidos. Segundo as reflexões do autor, a ideia da suposta superioridade masculina vem desde os primórdios da humanidade, pois surge da diferença biológica entre os sexos, assim como do próprio ato sexual, que pressupõe um agente ativo e um passivo, portanto, dominante e dominado. Essa estrutura ganhou legitimidade por ser compreendida como natural e foi se perpetuando ao longo do tempo, moldando a construção social do gênero, e influenciando também na vigência da heteronormatividade.

Tal teoria também ressalta que essa dominação é mutável, mas tem conseguido se manter graças à influência de instituições como a família, a escola, a igreja e o Estado, agentes que são citados também nas teorias marxistas (SANTOS et al., 2015). Com esse tecido social em mente é que serão analisados os discursos dos entrevistados, 
percebendo como os estereótipos de gênero influenciam os campos em que estão inseridos.

\section{Escolaridade e profissão}

A primeira parte do questionário levantou informações gerais sobre a escolaridade e profissão dos entrevistados. Percebe-se uma escolaridade alta entre os bailarinos: um entrevistado com ensino médio completo, dois cursando o ensino superior e três já tendo completado, além de um pós-graduado. Isso pode ser devido ao fato de o balé clássico ser historicamente e até hoje uma modalidade elitizada, com custos altos para sua prática (CAMINADA, 1999). Entretanto, com uma amostra tão pequena não é possível fazer afirmações sobre a realidade da modalidade como um todo.

Para as jogadoras de futebol, é ainda mais difícil tirar alguma conclusão, já que a pesquisa foi realizada com um grupo muito restrito. Como o questionário foi aplicado a um time universitário, é de se esperar que a grande maioria das atletas (91\%) esteja cursando o ensino superior, havendo também uma pós-graduada. Isso também se reflete na profissão das entrevistadas, já que $64 \%$ relataram ser estudantes, $27 \%$ atuam como estagiárias em suas áreas de formação e apenas uma pessoa (9\%) atua como engenheira mecânica. Entre as que estão atualmente na graduação, 57\% cursam Educação Física, e as demais estão em áreas variadas, como Ciências Sociais, Jornalismo, Design Gráfico, Odontologia, Engenharia de Produção e Administração.

Analisando pela ótica da categoria sociológica Identidade, apresentada por Marchi Júnior, Almeida e Souza (2019), a grande quantidade de estudantes de Educação Física no time pode se dever ao fato de a prática do futebol, e as experiências e relações desenvolvidas nele, tenham sido parte importante da formação da identidade dessas pessoas, chegando a influenciar nos objetivos profissionais e, portanto na escolha de cursar Educação Física.

Quanto à profissão dos praticantes de balé, três afirmaram serem bailarinos (43\%), sendo que um deles atua também como professor. Houve um estudante, e os demais atuam nos seguintes cargos: arquiteto, pesquisador e auxiliar administrativo. 
Uma informação adicional solicitada foi quantas horas de sua semana cada pessoa dedica à prática de balé ou futebol. Entre os bailarinos, grupo no qual havia tanto amadores quanto profissionais, houve grande disparidade nas respostas, que variaram desde uma hora e meia até 25 horas semanais de prática, resultando em uma média de aproximadamente dez horas. Como o grupo das jogadoras de futebol era mais homogêneo, as respostas obtidas também foram mais próximas, indo de duas a nove horas, com média de aproximadamente cinco horas por semana.

A alta proporção de profissionais entre os bailarinos, e o consequente número elevado de horas de dedicação, podem ser justificados, além da questão identitária citada anteriormente, por um achado do estudo de Andreoli (2010), que também consistia em entrevistas com bailarinos. $\mathrm{O}$ autor percebeu que os homens praticantes de dança tendem a buscar validação e legitimidade através da busca pela excelência em suas áreas, sendo mais raros os homens que praticam o balé apenas por lazer, como é comum na maioria dos esportes, como o próprio futebol.

\section{Histórico na modalidade}

Em um segundo momento, procurou-se saber qual a trajetória de cada indivíduo em sua prática: quando começou, os motivos e influências que levaram a ela e os desafios enfrentados nesse início.

Entre as mulheres que jogam futebol, a grande maioria (82\%) relatou ter iniciado a prática na infância, dos 4 aos 12 anos. Uma participante relatou ter iniciado aos 15 anos, por indicação médica como tratamento coadjuvante para um transtorno de déficit de atenção e hiperatividade. A outra jogadora que relatou ter começado na adolescência, aos 16 anos, esclareceu que essa foi a idade em que começou a participar de campeonatos, mas que jogava informalmente "desde que se conhece por gente", podendo-se considerar que também iniciou a prática na infância.

Essa presença do futebol na infância possivelmente se dá, pois, apesar de não haver muito incentivo para as meninas praticarem o futebol, este esporte está fortemente presente na cultura brasileira, de modo que as meninas acabam tendo 
contato com a prática (seja pela mídia, família ou escola), gostam e passam a praticar. Isso fica claro no seguinte relato:

\footnotetext{
"Eu sempre gostei de futebol por conta do meu pai que assistia toda semana. Mas ninguém me incentivou a jogar, pelo contrário, comecei sozinha porque gostava. Depois de muitos anos eles aceitaram."
}

Mais uma entrevistada também citou a influência do pai, que jogava futebol e frequentava jogos, enquanto outra relatou que via o irmão e os primos jogarem, e se interessou em participar. Percebe-se que o gosto pelo futebol desenvolve-se também com brincadeiras de rua entre amigos, que foram citadas por três participantes, não só nessa, mas em outras perguntas durante a pesquisa. Duas jogadoras também mencionaram projetos de ensino de futebol desenvolvidos em suas escolas.

No caso dos homens que praticam balé, temos uma situação diferente. Apenas dois começaram no balé quando crianças (7 e 8 anos), outros dois na adolescência (14 e 16 anos) e os demais apenas na fase adulta (19, 21 e 23 anos). Esse resultado de a maioria dos bailarinos iniciarem sua prática de forma mais tardia também foi encontrado por Andreoli (2010), que explica esse fenômeno pelas barreiras sociais enfrentadas por esses meninos que se interessam pelo balé. Muitas vezes as barreiras do preconceito somamse às econômicas, levando o homem a só iniciar sua prática quando consegue certa independência da família. Outro fato que pode ter influência na menor quantidade de meninos no balé é a presença muito menor da dança em geral, e especialmente do balé clássico, na mídia e no cotidiano do povo brasileiro, principalmente se comparados com esportes como o futebol.

Quanto ao incentivo para a prática, o bailarino que começou aos 7 anos falou ter incentivo dos pais, e o que iniciou aos 8 afirmou que se interessou ao ver as aulas de uma sobrinha da mesma idade. Uma tia foi citada por um bailarino como incentivadora, e os amigos por outros dois. Um relatou ter sido incentivado pela companhia em que já praticava outro estilo de dança, e outro que, após começar, teve muito apoio da professora. Além desses incentivos externos, dois relataram também motivações mais pessoais, como "curiosidade" e "necessidade criativa e de expressão". 
Também houve o questionamento se alguém do círculo de convivência dos entrevistados foi contra a prática da modalidade. Entre os homens, três não relataram nada, dois citaram a mãe, um citou que havia um "estranhamento por parte da família e pessoas mais velhas" e outro, que algumas pessoas diziam que balé não era para menino, o que era também o argumento das demais pessoas citadas como resistentes à prática, além do medo da rejeição social. Uma das mães que se opôs à prática do balé chegou a dizer que era "melhor ir para a academia".

No caso das mulheres, três não relataram nenhuma oposição. Uma citou que os colegas de escola a excluíam dizendo que era "coisa de sapatão" e que a mãe não a impedia, mas preferia que fizesse "coisas de menina". No caso de todas as demais que relataram alguma contrariedade (64\%), a oposição à prática também envolvia membros da família, como o pai, a mãe, ambos os pais, tios e avós. Os motivos alegados giram em torno da associação do futebol a algo masculino e a homossexualidade. Também houve afirmações de que o futebol feminino "não dá futuro" e há perigo de se machucar, além de avós que "preferiam que fizesse balé”.

Essas justificativas representam o senso comum predominante na sociedade, que se baseia nas noções de gênero já discutidas neste trabalho. Uma categoria sociológica que discute como esses conceitos vão se propagando e acabam influenciando o habitus dessas pessoas é a Socialização. Ela mostra que não só o ensino formal, mas também todas as interações sociais, vão sendo usados como forma de educar e transmitir tradições, crenças e valores morais (MARCHI JR; ALMEIDA; SOUZA, 2019). Isso pode ser construtivo, atuando no incentivo a uma prática e aquisição de valores desejáveis desse contexto, como persistência e disciplina. Mas também pode atuar na perpetuação de preconceitos, como os relatados nas entrevistas.

O profissional de Educação Física pode ter um papel fundamental nesse cenário, pois interfere diretamente no processo de socialização e formação de seus alunos, especialmente se forem crianças. Ressaltamos, portanto, a importância de formar profissionais capazes de refletir sobre estas questões sociais que permeiam o esporte e outras práticas corporais. Dessa forma, tais profissionais podem intervir de modo a incutir valores de aceitação de diferenças, e tentar evitar que outras influências construam uma visão de mundo pautada em padrões ou estereótipos, sejam de etnia, 
corpo ideal ou de gênero e sexualidade, que são os mais relevantes para a presente discussão. Esse é o objetivo e área de discussão também da categoria denominada Diversidade (MARCHI JR; ALMEIDA; SOUZA, 2019).

\section{Percepção de preconceito nos grupos sociais}

A terceira parte da pesquisa procurou obter, de forma mais objetiva, uma noção do preconceito sofrido pelos entrevistados em diferentes ambientes e grupos sociais, de acordo com sua própria percepção. Para isto, foi perguntado se, e com que frequência os/as entrevistados/das já sentiram qualquer tipo de preconceito em relação à sua prática, de balé ou futebol. As opções possibilitavam um espectro de "nunca" a "sempre", passando por "raramente", "algumas vezes" e "frequentemente".

De todo o questionário, essa foi a parte que permitiu uma visualização mais clara e quantitativa do preconceito sofrido, mas vale lembrar que está muito sujeita à interpretação de cada entrevistado. Os gráficos 1 e 2 mostram a frequência (em porcentagem) de cada resposta para os bailarinos e jogadoras de futebol, respectivamente. 
GRÁFICO 1- FREQUÊNCIA COM QUE HOMENS PRATICANTES DE BALÉ AFIRMARAM SOFRER PRECONCEITO EM DIFERENTES GRUPOS SOCIAIS7

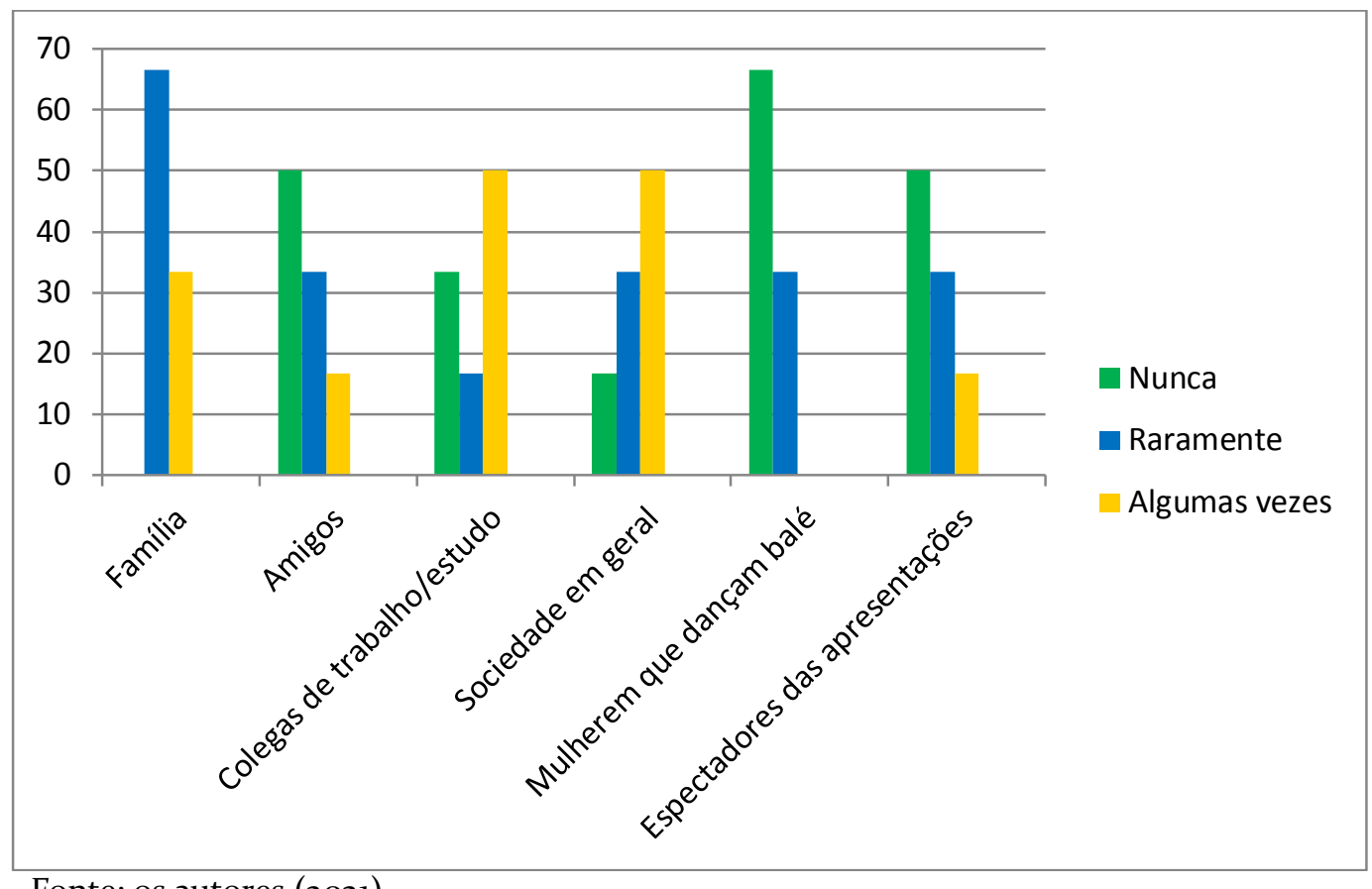

Fonte: os autores (2021).

GRÁFICO 2 - FREQUÊNCIA COM QUE MULHERES PRATICANTES DE FUTEBOL AFIRMARAM SOFRER PRECONCEITO EM DIFERENTES GRUPOS SOCIAIS

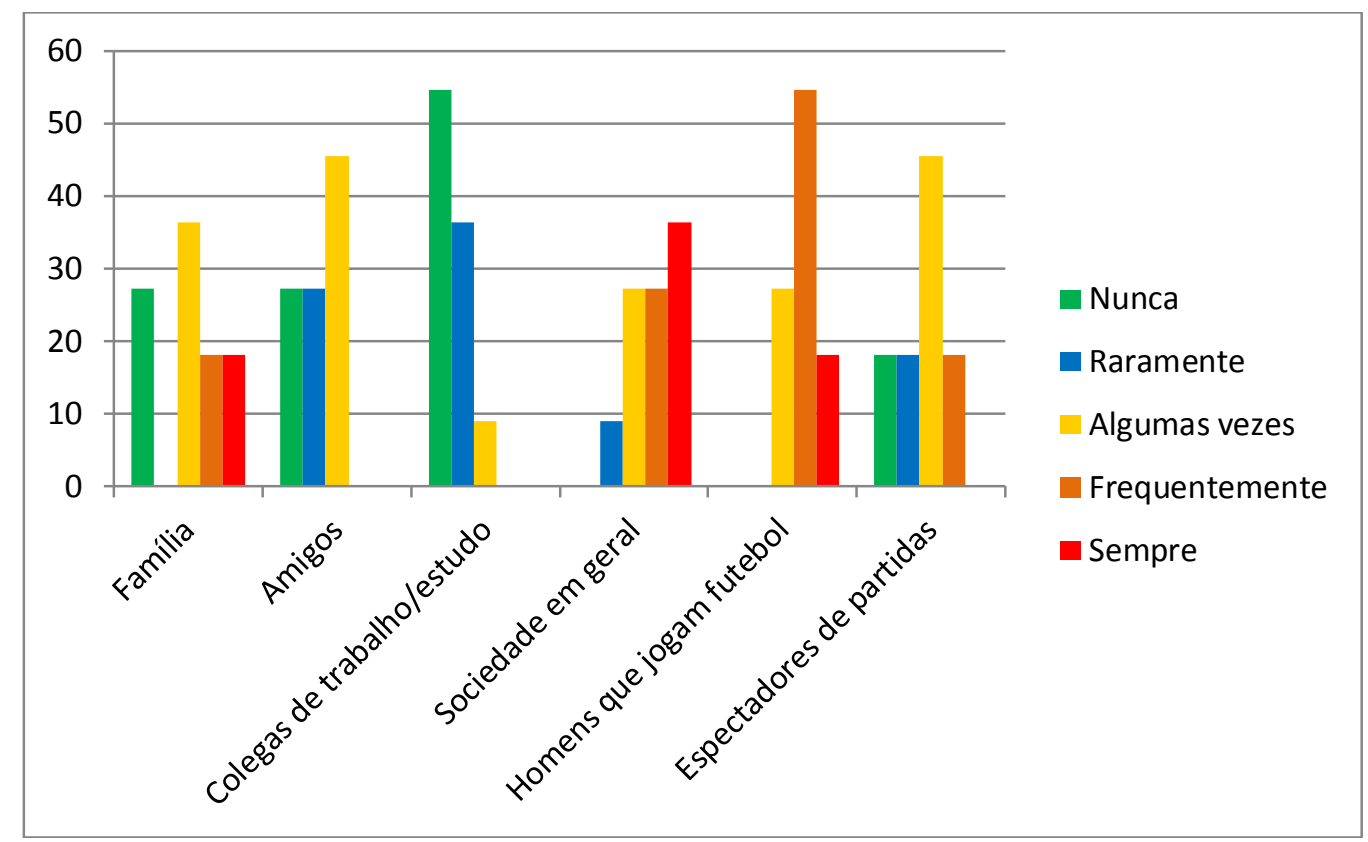

Fonte: os autores (2021).

${ }^{7}$ As opções “frequentemente" e "sempre” não aparecem na legenda, pois não foram selecionadas nenhuma vez. 
Observa-se que as mulheres indicaram sofrer com maior frequência o julgamento preconceituoso na maioria dos grupos sociais, com a exceção dos colegas de trabalho/estudo, em que as jogadoras de futebol tiveram maior proporção de respostas "nunca" e "raramente" que os bailarinos.

Entre os homens, percebe-se que os ambientes mais problemáticos são a família, os colegas e a sociedade em geral. Já na relação com as mulheres praticantes de balé, $67 \%$ dos bailarinos relataram nunca terem sofrido preconceito, e os demais, raramente sofrerem. Essa foi uma das principais diferenças percebidas entre essas duas realidades, já que $18 \%$ das jogadoras afirmaram sempre sofrer preconceito por parte dos homens que praticam futebol, $55 \%$ frequentemente, e o restante algumas vezes.

Um possível motivo para essa disparidade é uma diferença fundamental na organização das modalidades. No futebol, por ser um esporte, portanto tendo caráter competitivo, há a necessidade de separar as categorias feminina e masculina nos treinos e campeonatos, não havendo, dessa forma, grande interação. Como mulheres, as atletas sofrem os estigmas de fragilidade e incapacidade impostos pelo machismo estrutural na sociedade. Os atletas, de um modo geral, já têm essa visão de inferioridade das mulheres, estendendo seus preconceitos às jogadoras de futebol. Esse pensamento pode ser reforçado pela falta de contato com o futebol feminino, mas não se deve descartar a possibilidade de esse desdém e resistência dos homens ser uma forma, consciente ou não, de perpetuar essa estrutura machista, mantendo sua dominação e hegemonia neste campo.

Já o balé tem um objetivo mais estético e cênico. No balé clássico, principalmente quando falamos de balés de repertório ${ }^{8}$ geralmente há papéis definidos para cada gênero desempenhar, indo desde a encenação de um enredo até variações na própria técnica do balé. Assim, para produzir um espetáculo completo, especialmente

\footnotetext{
${ }^{8}$ Os principais balés de repertório contam uma história através das coreografias, incluindo os passos, gestos (ou pantomima) e expressões dos bailarinos, em conjunto com a música, cenário e figurinos. A maioria foi criada ao longo do século XIX, e continuam sendo remontados e adaptados por diversas companhias. Alguns dos mais famosos são: O Lago dos Cisnes, O Quebra Nozes, A Bela Adormecida, Dom Quixote e Giselle (CAMINADA, 1999).
} 
neste nicho, costumam ser necessários tanto homens quanto mulheres, que trabalham de forma conjunta.

Essa relação de cooperação entre bailarinos e bailarinas é um dos fatores que provavelmente gera uma relação mais harmoniosa entre os gêneros. Há também o fato de que os homens, apesar de sofrerem preconceitos por fazerem balé, ainda são o gênero dominante na sociedade, de modo que as bailarinas não trazem de sua criação uma noção estereotipada de que eles sejam inferiores, como acontece com as mulheres no esporte. Pelo contrário, geralmente as bailarinas admiram a força e habilidade dos homens no balé. Assim, quem desconhece a modalidade considera os bailarinos femininos, portanto inferiores. Por outro lado, dentro do contexto da dança, estes homens continuam tendo a imagem de força e vigor considerada padrão de masculinidade, e dessa forma não sofrem tal estigmatização.

A valorização do bailarino dentro do universo do balé também é aumentada justamente por sua escassez. Muitas escolas têm dificuldades em conseguir alunos homens para compor seus espetáculos, por isso oferecem descontos e bolsas para incentivá-los. Em companhias profissionais também há mais oportunidades, pois, apesar de ainda haver grande competitividade, a concorrência é muito menor que entre as bailarinas.

Uma situação que ilustra bem essa diferença é a seleção da Escola do Teatro Bolshoi do Brasil, uma das mais renomadas nacional e internacionalmente. Em 2019, concorriam às vagas 272 meninas e apenas 28 meninos (MARTENDAL, 2019). Apesar disso, o Bolshoi ainda é uma escola com grande proporção de meninos - cerca de $45 \%$ dos alunos - enquanto outras escolas importantes como do Teatro Municipal do Rio de Janeiro, de São Paulo e do Teatro Guaíra, variam em torno de 10\% dos alunos sendo do sexo masculino (NSC, 2017).

No futebol feminino, por ocorrerem competições separadas, o menor número de jogadoras tem o efeito contrário, reduzindo as oportunidades. O preconceito da sociedade em geral em relação ao futebol feminino diminui a procura pelo esporte, não só de praticantes, mas também de espectadores. A modalidade acaba tendo pouca visibilidade e, portanto, menos patrocínios. Gera-se um ciclo em que a mídia não exibe as partidas, porque não há retorno financeiro suficiente, e essa invisibilização prejudica 
cada vez mais o alcance e desenvolvimento do esporte. Assim, poucos times conseguem se manter financeiramente, havendo menos oportunidades de seguir no futebol profissionalmente (SOUZA, 2007).

Outra inferência que ilustra como as relações de hegemonia masculina da sociedade se reproduzem nestas modalidades, é o número de mulheres em cargos de responsabilidade nesses contextos. Não foi possível verificar esse fato nesta pesquisa especificamente, porém, Goellner (2021) relata que, além dos desafios como atletas, as mulheres têm ainda mais dificuldades para alcançar posições de comando no futebol, como técnica, diretora de times ou cargos em federações. Já no caso dos homens no balé, Andreoli (2010) aponta que, apesar de serem minoria como bailarinos, ocupam grande parte das posições de poder, como coreógrafos e diretores de companhias. O autor associa isso também à necessidade que os homens sentem de provar sua masculinidade através do sucesso e poder, mas não se pode deixar de observar que a menor proporção de mulheres em posições de liderança é algo presente na maioria dos setores da sociedade, inclusive neste em que os homens supostamente estariam em desvantagem.

\section{Perguntas abertas}

Na última parte do questionário, foram feitas perguntas abertas, a fim de compreender as opiniões e experiências dos participantes do estudo acerca dos desafios que envolvem o preconceito de gênero em sua modalidade. Por darem mais liberdade aos participantes, as respostas foram muito variadas, e não cabe analisá-las quantitativamente como feito no item anterior. Dessa forma, não serão expostas neste trabalho todas as respostas na íntegra. Ao invés disso, será apresentado um panorama geral dos temas mais citados em cada questão, e serão transcritas aquelas respostas que ajudaram a iluminar a discussão, indo ao encontro das hipóteses sugeridas pelo trabalho.

A primeira pergunta foi sobre qual seria, na opinião dos entrevistados, a origem do preconceito sofrido por eles. As questões discutidas sobre o machismo impregnado na estrutura da sociedade e o histórico da estereotipação dos gêneros foi o mais citado, de algumas formas diferentes. 
Entre as jogadoras, duas apontam diretamente o machismo (18\%), mas todas citaram de alguma forma as estruturas sociais levantadas, seja pela associação da mulher a trabalhos domésticos, ideia de inferioridade ou separação de brincadeiras por gênero. A colocação abaixo é um exemplo que cita indiretamente o machismo:

"Pode ser que venha de um histórico do papel social da mulher, que frequentemente esteve ligado à função de mãe e dona de casa apenas. Além disso, por exigir o máximo das capacidades físicas, o futebol é considerado um esporte masculino, indo de encontro com a ideia de sexo frágil e feminilidade da mulher."

Entre os bailarinos, 50\% tiveram essa opinião, seja citando diretamente o machismo, ou expressando-se de outra forma, como um bailarino que apontou o "tradicionalismo patriarcal que estereotipa corpos". Os demais citaram a falta de cultura e de conhecimento sobre o balé. Santos (2015) corrobora que, de modo geral, as classes menos privilegiadas não têm tempo e nem recursos para conhecer e apreciar qualquer tipo de arte mais erudita, como o balé, e essa falta de contato com a prática acaba reforçando seus preconceitos.

Partindo para a próxima pergunta, houve unanimidade entre os participantes de ambos os sexos que esse preconceito gera consequências negativas para sua modalidade. Todas as respostas abordaram que as crianças são desestimuladas a iniciar ou permanecer nessas práticas, causando a perda de talentos e atrasando o desenvolvimento da modalidade, inclusive dando relatos pessoais desse tipo de acontecimento.

\footnotetext{
"Muitas meninas boas não começam ou não continuam jogando por conta de preconceito. No meu caso, eu parei de praticar no ensino fundamental justamente por isso, pois não aguentava mais ser maltratada durante as aulas de futsal."
}

Entre as jogadoras de futebol, outros problemas foram citados, como falta de valorização, visibilidade, investimento e apoio, baixa remuneração, entre outros. As participantes a seguir apontam alguns desses problemas. 


\begin{abstract}
"Hoje vemos jogadoras dos maiores times brasileiros que tiveram/têm outras profissões pra se manter, porque o futebol feminino não é bem remunerado em sua grande maioria, consequentemente têm menos tempo para dedicar ao esporte. Os treinadores de times femininos estão aprendendo agora que o futebol é diferente entre homens e mulheres (assim como o vôlei feminino e masculino são diferentes, mas igualmente com qualidade). Tudo isso porque a sociedade acredita que mulher não sabe jogar bola."

"O futebol feminino não vai ser um grande espetáculo se as pessoas não quiserem assistir, enquanto houver pessoas com esse pensamento, perderemos visibilidade consequentemente não serão criadas oportunidades porque não vamos gerar o lucro que muitos patrocínios querem."
\end{abstract}

Também se vê nessa segunda fala a lógica de mercadorização do futebol apontada por Laibida (2013), ou seja, tratar o esporte como produto. Seguindo essa lógica comercial, o preconceito é prejudicial, pois causa o desinteresse do público, desse modo não há demanda para este produto de entretenimento, logo, não há investimentos.

Ao serem perguntados sobre se tinham tido sua orientação sexual relacionada com a prática, dois homens e duas mulheres afirmaram que não. Todos os demais relataram que já foram associados à homossexualidade devido à sua modalidade. Houve relatos nesse sentido tanto de praticantes heterossexuais quanto homossexuais, como o seguinte:

\footnotetext{
"As pessoas falavam quando eu era criança para "jogar bola, mas sempre ser feminina". Quando me descobri e comecei a namorar uma menina, as pessoas falavam "olha só, claro que ia ser assim". Muito errôneo isso, por que a gente vê que os moldes sociais estão aí também, relacionar esporte com homens, e mulheres que o praticam são ou querem ser homens, e por isso ficam com mulheres, é bizarro essa comparação, mas existe muito!"
}

Essa questão da sexualidade evidencia a categoria sociológica da Corporeidade, que enxerga o corpo como o modo que os seres humanos têm de se relacionar com o mundo. Desse modo, ao longo do crescimento dos sujeitos o corpo vai sendo carregado de símbolos sociais e uma valoração que muitas vezes acaba privando a liberdade e intensificando processos de exclusão e dominação (MARCHI JR; ALMEIDA; SOUZA, 2019).

Por fim, perguntou-se o que as mulheres achavam sobre o futebol ser considerado masculino. Uma relatou que não considerava algo negativo, que o rótulo não importa. As demais usaram expressões como "problemático", "um equívoco", 
"besteira”, "pensamento retrógrado e arcaico", além de retomarem alguns fatores envolvidos nessa concepção, já discutidos neste trabalho.

Ao fazer a pergunta análoga aos homens; o que eles pensam sobre o balé ser considerado feminino, um bailarino retomou o argumento da falta de conhecimento, também sendo citada a expressão “ignorância”. Também foi levantada a questão de que em outros países essa concepção não existe, de modo que a prática de balé é considerada natural para ambos os sexos, reforçando o argumento de Kimmel (1998) sobre a concepção de masculinidade se alterar em diferentes culturas. Um dos comentários foi o seguinte:

\footnotetext{
"Acredito que com tempo e com o conhecimento logo este assunto deixará de ser um tabu, mas até lá é preciso fomentar a informação até mesmo entre os jovens estudantes. Ballet é profissão de homem, independente de sua opção sexual. Exige força, agilidade, conhecimento corporal, técnica e uma grande vontade de fazer arte. Ballet é mais que a malha e sapatilha, suas vertentes são inúmeras, basta querer conhecer."
}

Um dos pontos interessantes nessa fala, assim como ocorreu em mais uma resposta desta questão, foi o fato de o bailarino exaltar as exigências físicas que sua prática possui. Assim, percebe-se que mesmo tratando-se de pessoas incluídas em ambientes teoricamente mais desconstruídos e que não se encaixam nos estereótipos da sociedade, a influência de toda uma criação baseada nessa dicotomia ainda está presente no habitus desses indivíduos, já que os bailarinos muitas vezes ainda buscam legitimar sua masculinidade através de idéias clássicas de força e virilidade. Andreoli (2010) já havia observado esse comportamento, o denominando como fenômeno do "bailarinoatleta", caracterizado pelo bailarino que procura mostrar que seu vigor físico é comparável ao de um atleta como forma de validar sua prática e reafirmar sua masculinidade.

De modo geral, percebe-se que a estrutura patriarcal sobre a qual a sociedade foi construída influencia todos os campos, tendo impacto mesmo que inconscientemente no habitus de todos os agentes envolvidos. Vale ressaltar que as mulheres, estando nesse esquema machista em condição de inferioridade, parecem ser 
mais prejudicadas, mas que os homens que não se encaixam no padrão de masculinidade, como os bailarinos, também são oprimidos por esse sistema.

\section{Considerações finais}

A partir dos fenômenos estudados e da bibliografia sobre o tema, foi concluído que a dicotomia entre os sexos foi historicamente construída, e, em função disso, o preconceito esteve e está presente na sociedade, inclusive vinculado fortemente a essas práticas corporais.

Apesar de ambas as modalidades apresentarem barreiras similares devido ao preconceito, ainda há mais mulheres jogando futebol do que homens praticando o balé, provavelmente porque o futebol em geral é mais popular e acessível, já o balé é uma prática mais elitizada e menos divulgada, sendo assim menos praticada. Contudo, as oportunidades no âmbito profissional das mulheres no futebol são menores se comparadas às dos homens no balé, tendo em vista que há pouquíssimos bailarinos no mercado para ocupar as mesmas companhias que as mulheres, diminuindo a concorrência, enquanto no caso das mulheres a falta de visibilidade dificulta a subsistência dos times, e assim diminuindo as oportunidades oferecidas para aquelas que buscam o profissionalismo.

Apesar de haver diferenças de funções entre homens e mulheres no balé, há uma relação de parceria e cooperação entre os gêneros, promovendo uma maior aceitação das mulheres para com os homens praticantes. Em contrapartida, no futebol não há interação entre os atletas de sexos distintos, possivelmente contribuindo para uma maior dificuldade da aceitação masculina em relação às mulheres praticantes da modalidade. Deve-se destacar que, estando inseridas em uma sociedade machista, os estereótipos para as mulheres já são de inferioridade, que são reforçados pela falta de diálogo, conhecimento e divulgação, além do interesse em manter o gênero masculino como hegemônico na modalidade.

Vale ressaltar que, apesar de estarem aparentemente em posições opostas, os preconceitos sofridos pelos homens no balé e as mulheres do futebol parecem partir de um mesmo conjunto de ideias e crenças. Em uma sociedade estruturalmente machista, 
existe uma forte misoginia, ou seja, uma aversão e desprezo a tudo que é relacionado ao feminino. Assim, do lado do futebol, surge a crença de que as mulheres, consideradas inferiores nessa mentalidade, são incapazes ou não deveriam praticar tal atividade estereotipada como masculina. Já no contexto do balé, os homens que praticam acabam sendo considerados "menos homens" pelas pessoas que têm esse tipo de preconceito. Por estarem associados a algo estereotipicamente feminino, principalmente na visão de pessoas sem conhecimento sobre balé, eles acabam sendo alvo dessas mesmas ideias misóginas.

Ao abrir a possibilidade de fazer um comentário ao fim do questionário, uma das participantes levantou uma questão interessante, que poderia ser investigada como desdobramento deste artigo. A entrevistada afirmou frequentar estádios e fazer parte de torcida organizada, e apontou que o preconceito nesses ambientes também é enorme, abrindo a possibilidade para uma análise dos desafios da mulher no futebol não só como jogadora, mas também como torcedora.

Este trabalho abordou de forma ampla os preconceitos sofridos por dois grupos distintos, levando a reflexões em diversos âmbitos. Essas observações certamente podem vir a inspirar estudos futuros, que poderão aprofundar problematizações mais específicas, seja explorando mais obras e conceitos de Bourdieu, ou buscando outros autores relacionados às categorias sociológicas citadas. Outra possibilidade para um trabalho futuro, que enriqueceria muito a análise, seria obter uma amostra maior de praticantes de cada modalidade, a fim de conseguir produzir uma pesquisa mais completa e representativa.

\section{Referências}

ANDREOLI, Giuliano Souza. Representações de masculinidades na dança contemporânea. 2010. Dissertação (Mestrado em Educação) - Faculdade de Educação, Universidade Federal do Rio Grande do Sul, Porto Alegre, RS, Brasil.

BERGER, Peter; LUCKMANN, Thomas. A Construção social da realidade. Petrópolis: Vozes, 1978.

BOURCIER, Paul. História da dança no ocidente. $2^{\mathrm{a}}$ ed. São Paulo: Martins Fontes, 
2001.

BOURDIEU, Pierre. A dominação masculina: a condição feminina e a violência simbólica. 15 $5^{\underline{a}}$ ed. Rio de Janeiro: Bertrand Brasil, 2019.

CAMINADA, Eliana. História da dança: evolução cultural. Rio de Janeiro: Sprint, 1999.

GIL, Antônio Carlos. Como elaborar projetos de pesquisa. 6ª ed. São Paulo: Atlas, 2017

GOELLNER, Silvana Vilodre. Mulheres e futebol no Brasil: descontinuidades, resistências e resiliências. Revista Movimento, Porto Alegre, v. 27, jan/dez, 2021.

GOELLNER, Silvana Vilodre. Mulheres e futebol no Brasil: entre sombras e visibilidades. Revista brasileira de Educação Física e Esporte, São Paulo, v.19, n.2, p.143-51, 2005.

A NOTÍCIA. Joinville tem maior concentração de meninos estudando balé no país. Joinville, 11 de novembro de 2017. Disponível em: $<$ https://www.nsctotal.com.br/noticias/joinville-tem-maior-concentracao-de-meninosestudando-bale-no-pais $>$ Acesso em 04/11/2019.

KESSLER, Cláudia Samuel. Se é futebol, é masculino? Sociologias Plurais, Curitiba, n. 1, p. 240-254, 2012.

KIMMEL, Michael S. A produção simultânea de masculinidades hegemônicas e subalternas. Horizontes Antropológicos, Porto Alegre, v. 4, n. 9, p. 103-117, 1998.

LAIBIDA, Luiz Demétrio Janz. Mercadorização do futebol na era da globalização. Sociologias Plurais, Curitiba, v. 1, n. 2, p. 172-195, ago. 2013.

LEITE, Miriam S. Significação da violência e heteronormatividade no contexto da prática curricular. Revista e-curriculum, São Paulo, v.7, n.1, 2011.

MARCHI JR, Wanderley; ALMEIDA, Bárbara Schausteck de; SOUZA, Juliano de. Introdução à Sociologia do Esporte. $1^{a}$ ed. Curitiba: Intersaberes, 2019.

MARTENDAL, Luan. Festival de Dança de Joinville: audição para o Bolshoi tem 300 candidatos. A Notícia. Joinville, 22 de julho de 2019. Disponível em: <https://www.nsctotal.com.br/noticias/festival-de-danca-de-joinville-audicao-para-obolshoi-tem-300-candidatos\#_=_> Acesso em 04/11/2019.

MARTINS, Mariani Zuaneti; SILVA, Kerzia Railane Santos; VASQUEZ, Victor. As mulheres e o país do futebol: intersecções de gênero, classe e raça no Brasil. Revista Movimento, Porto Alegre, v. 27, 2021. 
PISANI, Mariane da Silva. Futebol feminino: espaço de empoderamento para mulheres das periferias de São Paulo. Ponto Urbe, São Paulo, v. 14, 2014.

SANTOS, Renata Ferreira; et al. A dança como prática de lazer: algumas reflexões sobre homens, gênero e o balé clássico. Pensar a prática, Goiânia. v.18, n. 2, abr./jun. 2015.

SOUZA, Andrea Bittencourt de. Cenas do masculino da dança: representações de gênero e sexualidade ensinando modos de ser bailarino. 2007. Dissertação (Mestrado em Educação) - Universidade Luterana do Brasil, Canoas, RS, Brasil.

TEIXEIRA, Fábio Luís Santos; CAMINHA, Iraquitan de Oliveira. Preconceito no futebol feminino brasileiro: uma revisão sistemática. Revista Movimento, Porto Alegre, v. 19, n. 01, p. 265-287, jan./mar. 2013.

VIANA, Aline Edwiges dos S. Futebol: das questões de gênero à prática pedagógica. Revista da Faculdade de Educação Física da UNICAMP, Campinas, v. 6, ed. especial, p. $640-648$, jul. 2008. 